\title{
RESEARCH
}

\section{WHY SOME ELDERLY PEOPLE CANNOT USE THE HEARING AID}

Turkish Journal of Geriatrics

DOI: $10.31086 /$ tigeri.2020.189

2020; 23(4): 509-514

\section{n Süleyman ERDOĞDU}

CORRESPONDANCE

\section{'Süleyman ERDOĞDU}

Istanbul Haydarpasa Numune Training and Research Hospital, otorhinolaryngology, istanbul, Turkey

\section{Phone: +902165423232}

e-mail: suleymanerdogdu@gmail.com

Received: Aug 27, 2020

Accepted: Nov 24, 2020

${ }^{1}$ Istanbul Haydarpasa Numune Training and Research Hospital, otorhinolaryngology, Istanbul, Turkey

\section{Abstract}

Introduction: This study aims to investigate why some patients over 65 years of age cannot use their hearing aids.

Materials and Method: Hospital records between January 2018 and April 2019 identified 1,017 patients who received a hearing aid. Among them, 373 patients over the age of 65 were included in the study. It was questioned that they did not use the hearing aid.

Results: The reasons for not using the hearing aid are as follows: 9 patients couldnot distinguish sounds; 8 patients' cheap devices were not efficient; 6 patients showed a negative image so as not to be mentioned as disabled ; 6 patients' device battery runs out too quickly but use it as needd; 5 patients' device is making noise; 3 patients' device often fails; 3 patients reported it giving them headache; 2 patients feltirritated and that it injured theirear; 28 patients did not participate in the hearing rehabilitation program and did not contact the seller company to make the technical settings of the device.

Conclusion: Elderly patients complain that although they can hear voices, they have trouble understanding what the voices are saying, which are related but separate issues. Before applying the device, the age of the patient should be considered. All the details about the use must be taught to the person initially. It is very important to make technical adjustments depending on the software features of the device and routine control shouldbe included in the hearing rehabilitation program.

Key Words: Geriatrics; Presbycusis; Hearing Aids; Hearing Loss 


\section{INTRODUCTION}

Hearing disorders due to old age are called 'presbycusis'. This disorder is an age-related physiological change of the sensorineural part of the hearing organ. Depending on the severity of the problem, the most common complaint of patients with presbycusis is not being unable to hear the sound but the difficulty to understand what is being said (1).

While the incidence of presbycusis is $24-40 \%$ between the ages of 65-74, this rate increases up to $40-66 \%$ after the age of 75 . It is the third most common health problem in the geriatric population following high blood pressure and arthritis (2).

Hearing is the most important factor in the formation, development, and use of verbal communication. Presbycusis, affects the person not only organically but also psycho-socially and makes intense rehabilitation mandatory to provide the conditions that increase his/her quality of life. The first step toward rehabilitation is generally the selection of appropriate hearing aids. Otherwise, an unwise hearing aid recommendation will either be inadequate or destroy existing hearing over time. To get the most out of hearing aids, the use of the device should be binaural, the person should use the device as long as possible during the day, and both the patient and the patient's relatives should be well informed about the benefits of the device (3). Brooks stated that geriatric individuals need a longer adaptation period to hearing aids (4).

This study aims to investigate why some patients over 65 years of age do not use their hearing aids, even though they were prescribed and had already bought the devices.

\section{MATERIALS AND METHODS}

\section{Ethical approval}

This study has been approved by Haydarpasa Numune Training and Research Hospital Ethics Committee, Istanbul, Turkey. (date: 14.01.2019. no:2019/3).

\section{Study design and population}

We have studied a total number of 1017 patients requiring hearing aid who were admitted to Otorhinolaryngology outpatient clinic between January 2018 and April 2019. Age, gender and audiogram results were extracted from the hospital records. Age averages, air and bone track hearing threshold averages in the right and left ears as well as speech discrimination records were reviewed. 373 patients over 65 years of age were selected then (Tables 1-2). In one-on-one interviews, they were inquired about utilization of the hearing aids (Table 3), and their

Table 1. Audiogram Results of Patients

\begin{tabular}{|c|c|c|c|}
\hline \multicolumn{2}{|c|}{ Mean \pm SD } & \multirow{2}{*}{$\begin{array}{c}\text { Number of patients }(\mathrm{N}=1017) \\
\text { Mean } \pm \text { SD }\end{array}$} & \multirow{2}{*}{$\begin{array}{r}\text { Age } 65 \leq \\
(N=373)\end{array}$} \\
\hline & & & \\
\hline \multicolumn{2}{|l|}{ Age } & \multirow{2}{*}{$\begin{array}{l}69.20 \pm 14.03 \\
53.43 \pm 17.84\end{array}$} & \multirow{2}{*}{$\begin{array}{l}71.58 \pm 10.27 \\
54.35 \pm 18.03\end{array}$} \\
\hline \multirow{3}{*}{ Right ear } & $A C$ & & \\
\hline & $\mathrm{BC}$ & $43.49 \pm 20.42$ & $43.07 \pm 13.34$ \\
\hline & SD & $55.36 \pm 15.33$ & $54.80 \pm 16.27$ \\
\hline \multirow{3}{*}{ Left ear } & $A C$ & $54.95 \pm 18.18$ & $54.39 \pm 17.22$ \\
\hline & $\mathrm{BC}$ & $43.49 \pm 13.80$ & $42.67 \pm 13.92$ \\
\hline & SD & $56.67 \pm 35.22$ & $58.16 \pm 54.01$ \\
\hline
\end{tabular}


Table 2. Gender Distribution of Patients

\begin{tabular}{|l|l|c|c|c|c|}
\hline \multicolumn{2}{|c|}{} & \multicolumn{2}{c|}{ Number of patients (N=1017) } & \multicolumn{2}{c|}{$\begin{array}{c}\text { Age 65 } \\
(\mathrm{N}=373)\end{array}$} \\
\cline { 3 - 6 } \multicolumn{2}{c|}{} & $\%$ & $\mathrm{n}$ & $\%$ & \\
\hline \multirow{2}{*}{ Gender } & Female & 482 & 47.4 & 171 & 45.8 \\
\cline { 2 - 6 } & Male & 535 & 52.6 & 202 & 54.2 \\
\hline
\end{tabular}

answers were recorded (Table 4). It was found out that among these 373 patients, 42 patients who had received digital hearing aids behind the ears could not use them.

The severity of the hearing loss according to audiogram results was classified as mild hearing loss in the 20-40 dB HL range, moderate in the $40-60 \mathrm{~dB}$ $\mathrm{HL}$ range, advanced in $60-80 \mathrm{~dB} H \mathrm{HL}$ range, and very high in the above $80 \mathrm{~dB} \mathrm{HL}$ range (5).

Hearing aids constitute an important place in health expenditures even considering how the budgets are allocated by insurance institutions in the world and our country and the patients pay for their devices up to a certain extent. In a country with a population of around five million, like Finland, the amount paid for hearing aids is over 13 million Euros annually (6). In the USA in 1997, approximately $8 \%$ of individuals aged 65 experienced over use of hearing aids (7). In Turkey, this rate has remained relatively low. The rate of hearing aid usage is $4.7 \%$ according to Turkish Statistical Institute data (8).

In 2019, Turkey's population is approximately 83 million (83.154.997); 7.550 .727 (9.1\%) of the total population is aged 65 and over. Of these, 3.337.260 $(8 \%)$ are male; $4.213 .467(10.2 \%)$ is female (9).

\section{Statistical Analysis}

Data were analyzed with SPSS (Statistical Package for the Social Sciences) 15.00 package program. Descriptive statistical methods (frequency, mean, standard deviation) were used to evaluate the data.

\section{RESULTS}

In our study, the audiograms of 373 patients over 65 years of age had moderate sensorineural hearing loss and speech discrimination means of $55-58 \%$. The average age of the patients is $71.58 \pm 10.27$. Of these, 171 (45.8\%) were women, and 202 (54.2\%) were male (Table 2-3). The answers given by $42 \mathrm{pa}-$ tients who received the hearing aid but could not use it are listed in Table 3. Six of them stated that they used the device occasionally, rather than constantly because the battery was running out quickly. It was understood from the answers he/she gave that he/she did not use the device as a result of the communication between the company he/she purchased the device and these patients did not contact the hearing aid dispenser where they received the hearing aid battery regularly, did not adjust the device and did not receive rehabilitation training accordingly.

In response to question number 3, 17 patients stated that they bought low-quality devices, 9 patients had medium quality devices, and 5 patients

Table 3. Survey questions

1) Do you use the hearing aid?

2) What is your reason for not using the hearing aid?

3) What is the quality status of your hearing aid?

4) Did you contact the place where you bought your hearing aid? 
Table 4. The Reasons for 42 Patients not Using the Hearing Aids

\begin{tabular}{|l|l|l|}
\hline $\mathbf{n}$ & \multicolumn{1}{|l|}{$\%$} & Complain \\
\hline 9 & 21.43 & I can't distinguish sounds \\
\hline 8 & 19.05 & I was able to buy a cheap device. It was not efficient. \\
\hline 6 & 14.29 & Negative image: In order not to be called disabled \\
\hline 6 & 14.29 & The device battery is running out quickly. I use it when I need it \\
\hline 5 & 11.90 & The device is making noise. \\
\hline 3 & 7.14 & The device frequently fails. \\
\hline 3 & 7.14 & She's having a headache. \\
\hline 2 & 4.76 & It causes irritation and soreness in my ear. \\
\hline
\end{tabular}

received high-quality devices. Most of the elderly patients' complained not from being unable to hear voices but having trouble understanding the words.

\section{DISCUSSION}

A complete ear-nose-throat examination for the diagnosis of presbycusis necessitates an audiologic examination, where pure tone air and bony conduction thresholds, speech threshold, and the ability to distinguish tolerance levels to pure-voice and speech are determined (1). A study determined that hearing loss impairs the quality of life in individuals, causes depressive symptoms, and reduces functional capacity (10). Yurtogullari et al. reported in their study that presbycusis is an important cause of dementia and leads to the rapid development of dementia, so it is important to monitor hearing loss in geriatric patients closely and regularly (11).

The hearing aid is an amplifier, not a discriminator. In other words; a digital hearing aid raises the intensity of the incoming sound in accordance with patient's hearing thresholds, but does not directly assist in distinguishing or understanding speech in sensorineural hearing loss. The hearing aid user needs to be told what they can and cannot get from the device. It should also be explained that there may be some adaptation difficulties in the first days of wearing the device, such as using glasses. For this purpose, adaptation and orientation programs are applied as much as needed (1).

It is very important to give right information before applying the device by explaining in detail that hearing and understanding are related but separate issues. Having an adequate fitting suitable for the hearing loss and expectations of the person and using the binaural device if the conditions are suitable will also minimize the possible complaints. Also, clogging the tip of the ear plug and clogging the filter introduces the need to change the device battery at frequent intervals, which has been a deterrent to the use of the hearing aid. There may be complaints, such as the difficulty of placing the device mold in the ear, plugging the mold end of the plug, and blockage of the filter. It is very important to have routine check-ups and make technical adjustments, depending on the software features of the device for the conditions it encounters at home, on the street, on the television, and in a telephone conversation.

For this purpose, it was recommended to send our patients to the centers where they initially purchased their devices to perform device settings and maintenance. The plugs in the outer ear canal and 
ear mold were then cleaned and made available to the hearing aid.

Benett et al. (12) found that the problems encountered with hearing aid use are preventable and overcome problems with hearing aid application methods. A study conducted by Kahveci et al. (13) found that the method of hearing aid usage was not explained to the patients and the fact that the patients were older (70 and above) decreased the compliance to hearing aid use.

Orji et al (14) stated that 401.4 million people were in need of hearing aids. The great majority (83\%) of them do not use hearing aids.

The rate of patients who were recommended and reported hearing aids but did not buy hearing aids was found to be $22 \%$ in one study and $31.9 \%$ in another study, and the high cost of devices was stated as the reason for not having a device (14-16). Hamurcu et al. (15) found 32\%, Saatci et al. (8) $22 \%$ could not buy the device due to financial impossibilities. In our study, device cost is an important factor leading most of the patients to buy lower-quality devices. In their study, Hamurcu et al. (15) found a large group of patients who could not receive their device, even though the device was recommended. The reason for this is that the socioeconomic level of our country is low and the contribution paid by the social security is low, so most of the cost has to be covered by the patient. In our study, it was understood that 8 patients who bought cheap devices (19.05\%) gave up using their devices because they had primitive technology.

A study by Mc Pherson (16) on affordable hearing aids investigated the effectiveness of the elderly and affordable over the counter devices to provide access to the many patients with hearing loss. They conclude that further research and more of these tools to provide improved rehabilitation results should be prioritized.

In their study, Saatci et al. (8) found that the most influential obstacle in the use of hearing aids is the external recognition of the device and the idea that it shows the user as elderly or disabled. This problem was detected in six patients (14.29\%) in our study.

In their study, Hamurcu et al. (15) found the reasons for device incompatibility to be noise from the device, inability to speak in crowded environments, and infections occurring in the outer ear canal. In the study conducted by Kirkim et al. (17), the fact that device maintenance and use have difficulties, especially in elderly patients living alone, reduces the device's benefits.

Care should be taken to clean the ear mold, and an ear examination should be done periodically. It is seen that as the educational level increases, complaints about device use decrease.

Kenar et al. (18) stated that in a review examining the problems encountered in the use of hearing aids in the adult population, digital hearing aids, which have become widespread recently, decrease the usage problems considerably.

In the general evaluation of unilateral hearing aid users in the geriatric group, Senkal et al. (19) did not find a statistically significant effect of hearing aid usage time on the quality of life. In the same study, they found that the use of hearing aids increased their communication ability and strengthened self confidence.

The fact that the device is not an artificial ear but rather a headset should be explained to the patient, and all device related details should be taught to the user at the beginning.

\section{CONCLUSIONS}

Presbycusis is common in the geriatric population. It is recommended to use hearing aids for its rehabilitation. To receive maximum benefit from hearing aids, the use of the device should be binaural and the person should use the device as long as possible during the day. Our study showed that a 
considerable percentage of the elderly population cannot use hearing aids even though having paid for them; and, the main reason for that was shown to be insufficient communication among physicians, audiologists and patients. Patients and their relatives should be informed about the benefits and us-

\section{REFERENCES}

1. Ozkan S. Hearing, Voice and Speech Disorders in The Elderly. Turkish Journal of Geriatrics 1998;1(2):72-75. (in Turkish)

2. Aksoy S. Age-related hearing loss and auditory rehabilitation. Journal of Exercise Therapy and Rehabilitation 2015;4:1-2.(in Turkish)

3. Cakir O, Yildirim G, Kumral TL.et al. Presbycusis and Rehabilitation in Old Age. The Medical Journal of Okmeydanı Training and Research Hospital 2013;29(2):116-120. (DOl:10.5222/otd. supp2.2013.116). (in Turkish)

4. Brooks DN. The time course of adaptation to hearing aid use. $\mathrm{Br} J$ Audiol 1996;30(1):55-62. (PMID:8839367).

5. Jerger J, Jerger S. Measuring of hearing in adults. In: Paparella MM, Shumrick DA, eds. Otolaryngology, 2nd ed. WB Saunders, Philadelphia 1980. pp. 1226.

6. Akyildiz N. Ear Diseases and Microsurgery, vol.1. Scientific Medicine Publisher, Ankara, Turkey 1998, pp. 15-40.(in Turkish)

7. Cox RM, Alexander GC. The abbreviated profile of hearing aid benefit. Ear and Hearing 1995;16(2):17686. (PMID:7789669).

8. Saatci O, Polat B, Cakir N. Hearing loss and stigma. Praxis of Otorhinolaryngology 2017;5(2):63-69. (DOI: 10.5606/kbbu.2017.83703).(in Turkish)

9. Turkish Statistical Institute. Population by Years. Age Group and Sex. Census of PopulationABPRS.2019.[Internet]Availablefrom: http://www.turkstat.gov.tr/UstMenu.do?metod=temelist. Accessed: 01.07.2020.

10. Lupsakko TA, Kautiainen HJ, Sulkava R. The non-use of hearing aids in people aged 75 years and over in the city of Kuopio in Finland. Eur Arch Otorhinolaryngol 2005; 262: 165-169.(PMID: 15133689).

11. Yurtogullari $S$, Kocan EG, Vural G, Gumusyayla $S$, Babademez MA, Bozdemir K. The Relationship of age of the device. They should be motivated to use the device. The doctor and audiologist should be informed about the problems in using the device. Most important of all, using the latest technology device should be encouraged.

Presbycusis with Cognitive Functions. Turkish Journal of Geriatrics 2020; 23(1): 75-81. (DOI: 10.31086/ tjgeri.2020.140).

12. Bennett RJ, Lévesque AL, Meyer CJ, Eikelboom $\mathrm{RH}$. Exploring Hearing Aid Problems: Perspectives of Hearing Aid Owners and Clinicians. Ear Hear 2018;39(1):172-187.(PMID: 28787315).

13. Kahveci OK, Miman MC, Okur E, Aycicek A, Sevinc $S$, Altuntas A. Hearing aid use and patient satisfaction. The Turkish Journal of Ear Nose and Throat 2011;21(3):117-121. (PMID: 21595614).(in Turkish)

14. Orji A, Kamenov K, Dirac N, Davis A, Chadha S, Vos T. Global and Regional Needs, Unmet Needs and Access to Hearing Aids. International Journal of Audiology 2020;59(3):1-8. (PMID: 32011190).

15. Hamurcu M, Sener BM, Atas A, Atalay RB, Bora F, Yigit O. Evaluation of Patients Satisfaction with Hearing Aids. Electronic Journal of Otolaryngology Head and Neck Surgery 2012;11(2):26-31. (in Turkish)

16. McPherson B, Wong ETL. Effectiveness of an affordable hearing aid with elderly persons. Disabil Rehabil 2005; 27: 601-609. (PMID: 16019870).

17. Kirkim G, Serbetcioglu MB, Mutlu B. Assessment of Patient Satisfaction for Hearing Aids Using the Turkish Version of International Outcome Inventory for Hearing Aids. Journal of Ear, Nose \& Throat and Head \& Neck Surgery 2008; 16(3): 101- 107.(in Turkish)

18. Kenar F, Babademez MA. Problems encountered with hearing aids in adult population. Journal of ENT Updates 2015; 5(1): 41-47. (DOI:10.2399/jmu. 2015001001).

19. Senkal OA, Kose A, Aksoy S. Assessment of Geriatric Patient's Satisfaction on Hearing Aids and Their Influence on Quality of Life. Turkish Journal of Geriatrics $2014 ; 17$ (4):389-396. (in Turkish) 